\title{
The Persistent Problem of Malnutrition in India
}

\author{
K VIJAYARAGHAVAN* \\ Senior Deputy Director (Retd), National Institute of Nutrition, Hyderabad 500 007, India
}

(Received on 13 May 2016; Accepted on 10 June 2016)

\begin{abstract}
India contributes to about a third of the total number of the under-nourished in the world. Generally, under-nutrition is assessed as under-weight or stunting and/or wasting. The Periodic surveys by the National Nutrition Monitoring Bureau (NNMB) and the National Family Health Survey (NFHS) reveal unacceptably high prevalence of under-weight and stunting among Indian children of 0-59 months of age. About 19\% Indian children are born with low birth weight $(<2500$ g) due to chronic maternal under-nutrition. About a third of the rural adults also have chronic energy deficiency (BMI <18.5). Anaemia, as assessed by low haemoglobin, is widespread among the vulnerable segments of population. Calorie inadequacy, with or without protein inadequacy, is the predominant dietary problem and a large majority of individuals consume less than $70 \%$ of the recommended dietary allowance of micronutrients. Though the periodic surveys by NNMB and/or NFHS indicate gradual reduction in under-nutrition over time, its prevalence is unacceptably high. However, all the nutrient intakes show a decline over the last four decades. Even if India achieves the WHO Assembly's first of the six global nutrition targets of $40 \%$ reduction by 2025 in the extent of stunted in under- 5 children, unacceptably high proportion of one in four children might still be stunted. Nutritional anaemia and sub-clinical vitamin A deficiency are widespread. Deficiencies of other micronutrients like riboflavin, folic acid, vitamin $\mathrm{B}_{12}$ and vitamin $\mathrm{D}$ are also rampant. Among the adults, while there is a gradual reduction in chronic energy deficiency over the four decade follow-up period, there is also a gradual increase in overweight and obesity. Substantial increases in economic growth experienced over the past two decades did not translate into a similar substantial reduction in under-nutrition, perhaps due to unequal economic growth excluding the poor. Nutrition-sensitive interventions and programmes in agriculture, social safety nets, early child development, education, women's empowerment and access to safe drinking water and sanitation have enormous potential to scale-up and enhance the effectiveness of nutrition-specific interventions.
\end{abstract}

Keywords: Persistent Under-Nutrition; Underweight; Stunting; Wasting; NNMB; NFHS; RSOC; DLHS; Dietary Adequacy; Time Trends; Biochemical Assessment; Anthropometry; BMI; Nutrition Intervention

\section{Introduction}

Nutrition forms the foundation for normal human health and development. The process of malnutrition often starts in utero, and the first 1000 days of a child's life between a woman's pregnancy and child's 2nd birthday are considered important for child's normal growth and cognitive development and may last, particularly for girls and women, throughout the life cycle. Besides posing threats to woman's own health and productivity, under-nutrition that contributes to stunting and underweight in a woman's adult life increases the chance of her children being born malnourished (Gillespie and Flores, 2000). Nutritional status as a key indicator of Millennium Development
Goal (MDG) of poverty and hunger is an important first step in recognizing that policies, programmes and processes to improve nutrition outcomes have a role to play in global development (UNSCN, 2004).

Malnutrition is a global problem of staggering size affecting almost one in three people on the planet, large enough to threaten the world's sustainable development ambitions (IFPRI, 2015). In the developing world, due to persistently widespread under-nutrition, millions of children do not grow and develop to their full potential, leading to loss of millions of lives. The joint estimates of WHO,UNICEF and World Bank (2012) reveal that in South East Asia, the combined prevalence of moderate and severe

*Author for Correspondence: E-mail: drk.vijayaraghavan@gmail.com 
underweight (weight $<\mathrm{M}-2$ SDfor age) was $16.6 \%$, contributing to a total number of about 8.8 million under five children. About $27.6 \%$ of children were either moderately or severely stunted. Recognizing the need for accelerated global action to address the pervasive and corrosive problem of the double burden that includes both under-nutrition and over-nutrition, the World Health Assembly endorsed a comprehensive implementation plan on maternal, infant and young child nutrition. These specified a set of six global nutrition targets that aims, by 2025 , at $40 \%$ reduction in the number of children under-5 who are stunted; $50 \%$ reduction of anaemia in women of reproductive age; $30 \%$ reduction in low birth weight; reduction and maintenance of childhood wasting to less than $5 \%$ with no increase in childhood overweight and increase the rate of exclusive breast-feeding in the first 6 months up to at least 50\% (WHO, 2014). India is one of the twenty-four countries that together account for more than 80 per cent of the global burden of chronic undernutrition (stunting or low height for age). Due to large population size, it contributes to $31.2 \%$ of the total number of the stunted in the world (UNICEF, 2009). Paucity of reliable and comparable data from all parts of the country is a definite obstacle towards a realistic and disaggregated problem definition. Therefore, the first step in the formulation of any strategy to combat under/malnutrition is nutrition assessment to determine the magnitude and distribution of malnutrition in different geographic areas, and to identify the at-risk groups and the contributing factors.

\section{Measuring Under-nutrition in India}

The extent of malnutrition is assessed mainly in terms of nutritional deficiency signs by clinical examination; or determining sub-clinical changes (early stages of deficiency having no noticeable clinical symptoms and signs), with the help of nutritional anthropometry and/ or biochemical evaluation. However, clinical examination and nutritional anthropometry are routinely used, as they are relatively simple and do not require sophisticated equipment. Furthermore, estimation of nutrients or their metabolites in blood and other tissues through biochemical evaluation helps in determining the extent of sub-clinical under-nutrition. The National Nutrition Monitoring Bureau (NNMB), established as early as in 1972 under the auspices of the Indian Council of Medical Research (ICMR) in 10 states to start with and covering geographically about two thirds of the country, was the first serious attempt to conduct annual nutrition surveys including clinical examination, anthropometry, and dietary evaluation both at the household and individual levels. Biochemical evaluation to assess anaemia and subclinical vitamin A deficiency was also carried out periodically. The data was collected at the state level by dedicated state level trained teams of qualified investigators under the technical supervision of the National Institute of Nutrition, Hyderabad. The unique feature of the NNMB, apart from organizing annual nutrition surveys on a continuous basis, was determining the time trends in diet and nutritional status of vulnerable groups by organizing repeat surveys in the same villages at periodic intervals (NNMB, http:/ /nnmbindia.org/aboutus.html)

Subsequently, the Ministry of Health and Family Welfare (MOHFW), Government of India, initiated a large-scale nation-wide multi-round collaborative survey, NFHS (National Family Health Survey) with major financial support from the USAID and UNICEF. International Institute of population Sciences (IIPS), Mumbai is the nodal agency, responsible for providing coordination and technical guidance. IIPS collaborated with a number of Field Organizations located in universities and institutes of national repute responsible for conducting surveys in one or more states. The First National Family Health Survey (NFHS-1) was conducted in 1992-93. It collected extensive information on population, health, and nutrition (heights and weights of children $<3$ years of age and assessment of haemoglobin among women, including pregnant women) and young children (IIPS, 1995).While NFHS-2 was conducted in 1998-99 in all 26 states of India, the NFHS-3 was carried out in 2005-2006 in 29 states of India. The NFHS-4 was initiated in 2014-15 in all the 29 states and the six union territories; the report is still awaited. While NNMB and NFHS present data at the state and national level, the District Level Household Surveys (DLHS) sponsored by the Ministry of Health and Family Welfare (MOHFW), presented household data at the district level to obtain 'district nutrition profiles' that would help in the preparation of district specific intervention programmes. The DLHS-2 was carried out during 1998-99, DLHS-3 in 2002-04 (IIPS, 2010) and DLHS4 in 2012-13 covering 611 districts, with IIPS as the national nodal agency (IIPS, 2012). In addition, the Department of Women and Child 
Development (DWCD) of Government of India sponsored a nationwide rapid household survey on children (RSOC) in 2013-14 in 28 states and the Union Territory of Delhi, with the main focus on development in children below 6 years of age, and well-being of their mothers with respect to maternal care (Government of India, 2015). This brief review of the current situation on nutrition status of vulnerable groups and the time trends in the extent of undernutrition is mainly based on the results of these surveys.

\section{Current Status}

Indian children of poorer socio-economic communities, a majority of whom are generally born small for date, have a low birth weight (LBW), due to chronic undernutrition and poor health of their mothers. LBW is an accepted indicator of new-born's chances of survival, growth and health (UNICEF, 2004). The RSOC reported a prevalence of low birth weight $(<2500 \mathrm{~g})$ of about $18.6 \%$, with no differences between rural $(18.7 \%)$ and urban $(18.4 \%)$ areas. However, the data is based on the $69 \%$ of sampled infants, who were weighed within 24 hours of birth at different institutions, where the deliveries took place (UNICEF 2009). Furthermore, the reliability of data is also influenced by the accuracy of the weighing scales used. UNICEF (2014) based on the reanalyzed NFHS data had reported that the extent of LBW in 20052006 was about $28 \%$.

\section{Anthropometric Assessment of Under-nutrition}

Under-nutrition is generally assessed as under-weight (weight for age $<-2$ SD of the WHO Growth Standards median) or stunting (height for age $<-2$ SD of the WHO Growth Standards median) and/or wasting (weight for height $<-2 \mathrm{SD}$ of the WHO Growth Standards median). While stunting reflects the cumulative effects of under-nutrition and infections since and even before birth, and is an indication of long-term restriction of a child's growth potential, wasting is an indicator of weight loss or short duration malnutrition. Under-weight reflects wasting, stunting, or both (WHO, 2010). The prevalence rates of different forms of under-nutrition among 0 to 59 month old children based on the most recent national rapid survey of children during the years 2013 and 2014 are presented in Table 1 (DWCD, 2015).
Table 1: Prevalence (\%) of Under-nutrition - 0-59 months

\begin{tabular}{llccc}
\hline $\begin{array}{l}\text { Type of under- } \\
\text { nutrition }\end{array}$ & Degree & India & Rural & Urban \\
\hline Stunting & Moderate* $^{*}$ & 21.4 & 22.5 & 18.8 \\
& Severe** $^{* *}$ & 17.3 & 19.1 & 13.2 \\
Wasting & Moderate* $^{*}$ & 10.5 & 15.1 & 15.0 \\
& Severe** & 4.6 & 4.5 & 4.8 \\
Underweight & Moderate* & 20.0 & 31.6 & 24.3 \\
& Severe** & 9.4 & 10.6 & 6.9 \\
\hline
\end{tabular}

*Moderate: < Mean - 2 SD to < Mean- 3 SD; **Severe: < Mean $-3 \mathrm{SD}$

Source: RSOC 2013-14

The extent of underweight (30\%) and stunting (39\%) among children between 0-59 months of age is still unacceptably high. The percentage of severe acute malnutrition (SAM) is 4.5. SAM is defined by a very low weight for height (below-3 SD of the median WHO growth standards). Under-nutrition in rural children is marginally higher than the urban children.

NNMB is the only institution which collected, on a continuous basis, comprehensive data on dietary status, nutritional deficiency signs and nutritional anthropometry on all the available members in the selected households. The annual NNMB surveys are restricted to the rural areas only and the extent of child under-nutrition is presented for 1-5 year children. About $42 \%$ of $1-5$ year old children were underweight and about $46 \%$ were stunted (NNMB, 2012). In absolute terms, the number of children either underweight or stunted is between 63 and 66 million. India contributes to about 40 percent of the world's stunted children under the age of 5 years and nearly 50 percent of the wasted children (UNICEF 2013). There is considerable overlap of stunting and underweight. About $74.5 \%$ of the under-weight children were also stunted and $77.6 \%$ of the stunted children were underweight as well (Nandy et al., 2005). Among the adults, malnutrition is measured using body mass index (BMI), which is defined as the weight in kilograms divided by the square of the height in metres $\left(\mathrm{kg} / \mathrm{m}^{2}\right)$. BMI $<18.5$ indicates chronic energy deficiency, 18.524.9 indicates normal weight, BMI 25.0-29.9 indicates overweight and BMI $\geq 30.0$ indicates obesity. While about a third of the rural men have chronic energy deficiency (CED), $10 \%$ of men and $13.5 \%$ women are also either overweight or obese. Thus, it is clear 
that Indians of low socio-economic group living in rural areas are exposed to malnutrition from birth to adulthood.

\section{Nutrition Deficiency Signs}

The recent NNMB surveys indicate that clinical forms of under-nutrition are not as common. The prevalence of florid clinical forms of protein energy malnutrition (PEM) like kwashiorkor/marasmus among children is almost absent. Currently, SAM children (weight for height $<-3 \mathrm{SD}$ of the median WHO growth standards) - about $4.5 \%$ - are provided with clinical nutritional rehabilitation. The extent of clinical micronutrient deficiencies of vitamin $\mathrm{A}$, as measured by Bitot spots is $0.2 \%$ with almost absence of corneal xerophthalmia. B-Complex deficiency manifestations like angular stomatitis and glossitis $(0.3 \%)$ are also not common.

\section{Biochemical Assessment}

Micronutrient deficiencies, generally also known as hidden hunger; like iron deficiency anaemia and vitamin A deficiency are considered of public health significance. Since diagnosis of clinical anaemia is very subjective, its prevalence is evaluated by estimation of haemoglobin. NNMB conducted haemoglobin surveys by cyanmethemoglobin method in different physiological segments of rural population in different states (NNMB, 2003). Nutritional anaemia, as indicated by low haemoglobin, is widespread among pre-school children (66.9\%), adolescent girls (69\%), pregnant women (74.6\%) and lactating women (78.1\%). NFHS survey revealed that about a quarter of men also had evidence of anaemia (NFHS-3, 2006). NNMB (2005) also carried out a survey of blood vitamin A levels to assess sub-clinical vitamin A deficiency in pre-school children. Even though the extent of Bitot spots in preschool children was negligible, sub-clinical vitamin A deficiency was widespread. About $62 \%$ had low serum retinol $\leq 0.70$ $\mu \mathrm{mol} / 1$ and $21.5 \%$ had levels considered as deficient $(\leq 0.35 \mu \mathrm{mol} / \mathrm{l})$ as per WHO criteria (WHO, 1996).

\section{Dietary Status}

Consumption of nutritionally inadequate diets is the major direct reason for the widespread prevalence of under-nutrition. Household diet survey and 24 hour individual dietary recall surveys carried out by NNMB
(2012) reveal that the median intakes of almost all the nutrients are below the recommended dietary allowances (RDA) for Indians. Calorie inadequacy, either with protein adequacy or inadequacy, is the predominant dietary problem with about 41 to $51 \%$ of children under 6 year of age showing calorie inadequacy. On the other hand, 60 to $71 \%$ adult males and females consume energy and protein adequate diets (Table 2).

Dietary inadequacy of micronutrients like vitamin A, iron and vitamins B-complex was common. More than two thirds of both the households and individuals consumed less than $70 \%$ of RDA of micronutrients. In the case of children aged 1-3 years, over $80 \%$ consumed less than $70 \%$ RDA of vitamin A, while almost $70 \%$ consumed less than 50\% RDA of iron.

An observation of programmatic significance and, perhaps a contributing factor for widespread child under-nutrition was the unfavourable intra-family distribution of the diets (in terms of energy) to preschool children. Even when the adult counterparts had an adequate energy intake in the same households, about one-third of the preschool children were fed an inadequate intake of energy, and only about $7 \%$ of both the pre-schoolers and their parents were consuming inadequate amounts of energy. The extent of energy inadequacy within the same families was

Table 2: Protein \& Calorie Adequacy Status

\begin{tabular}{|c|c|c|c|}
\hline Age group (Years) & P-C- & $\mathrm{P}+\mathrm{C}-$ & $\mathrm{P}+\mathrm{C}+$ \\
\hline $1-3$ & 13.4 & 37.6 & 49.0 \\
\hline $4-6$ & 3.4 & 37 & 59.7 \\
\hline $7-9$ & 4.9 & 39.3 & 55.8 \\
\hline $10-12$ boys & 11.4 & 47.8 & 40.7 \\
\hline $10-12$ girls & 14.3 & 42.6 & 43.1 \\
\hline 13 - 15 Boys & 18.4 & 54.5 & 27.1 \\
\hline 16 - 17 Boys & 21.2 & 50.9 & 28.0 \\
\hline 7 - 17 Girls & 21.5 & 36.3 & 42.2 \\
\hline Men sedentary & 18.0 & 17.9 & 63.4 \\
\hline Pregnant Women & 16.4 & 10.4 & 70.7 \\
\hline Lactating Women & 24.0 & 10.8 & 60.2 \\
\hline NPNL* Women sedentary & 16.4 & 10.4 & 70.7 \\
\hline
\end{tabular}

P-C-: Protein \& Calorie Inadequate; P+C-: Protein Adequate \& Calorie Inadequate,

$\mathrm{P}+\mathrm{C}+$ : Protein \& Calorie Adequate. *Non-pregnant non-lactating Source: NNMB, 2012 
much less in adolescents and school-age children than in preschool children (Vijayaraghavan et al., 2002).

\section{Time Trends in Under-nutrition}

The NNMB surveys indicate a striking reduction in the prevalence of severe clinical of PEM like kwashiorkor and marasmus, which are now rare in a routine nutrition survey. Signs of vitamin A deficiency and B-complex deficiency (angular stomatitis) in preschool children also declined significantly (Fig. 1).

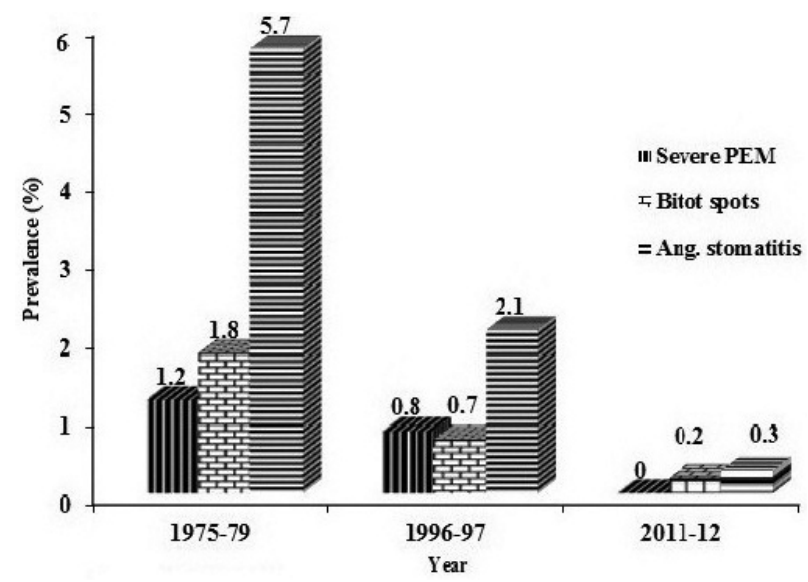

Fig. 1: Time trends in Nutrition deficiency in children (Source: NNMB Report \# 26, 2012)

Although clinical signs of deficiencies, once so common are not as frequent, subclinical vitamin deficiency and nutritional anaemia are widespread, as earlier indicated, indicating the need for focused micronutrient deficiency control programme.

\section{Diet and Nutrient Consumption}

Interestingly, all the nutrient intakes showed a decline over the four decades. As the rural diets consist predominantly of cereals with small quantities of pulses and other food items, to determine time trends, average energy and protein consumption (\%RDA) among the adults was considered, which showed a decline of about $20 \%$ over the last four decades (Fig. 2).

\section{Anthropometry}

NNMB repeat surveys indicated that despite $45 \%$ reduction in the extent of underweight among $1-5$ years old rural children between 1975-79 (75.5\%) and 2011-

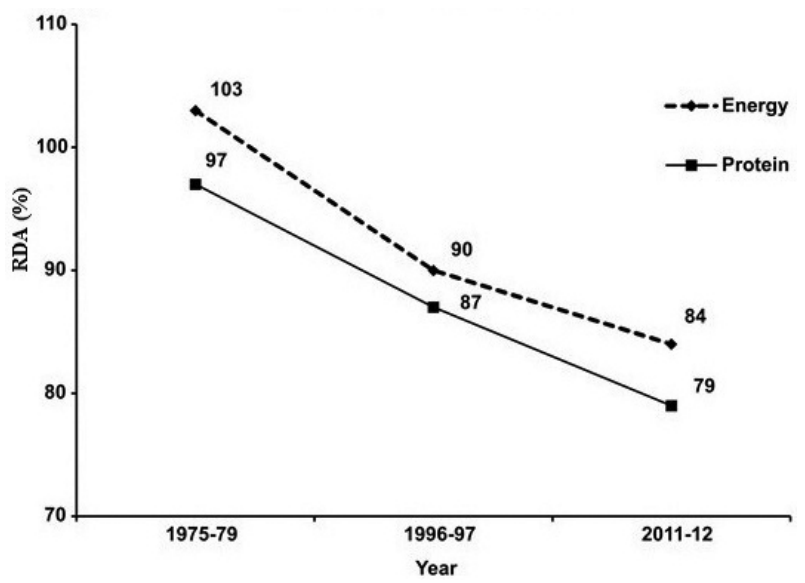

Fig. 2: Time trends in Energy and Protein intakes among Adults - \%RDA (Source: NNMB Report \# 26, 2012)

$12(41.1 \%)$, underweight remained still widespread. There was a parallel increase in the percentage of normal weight for age from $24.5 \%$ to $58.9 \%$ (Fig. 3).

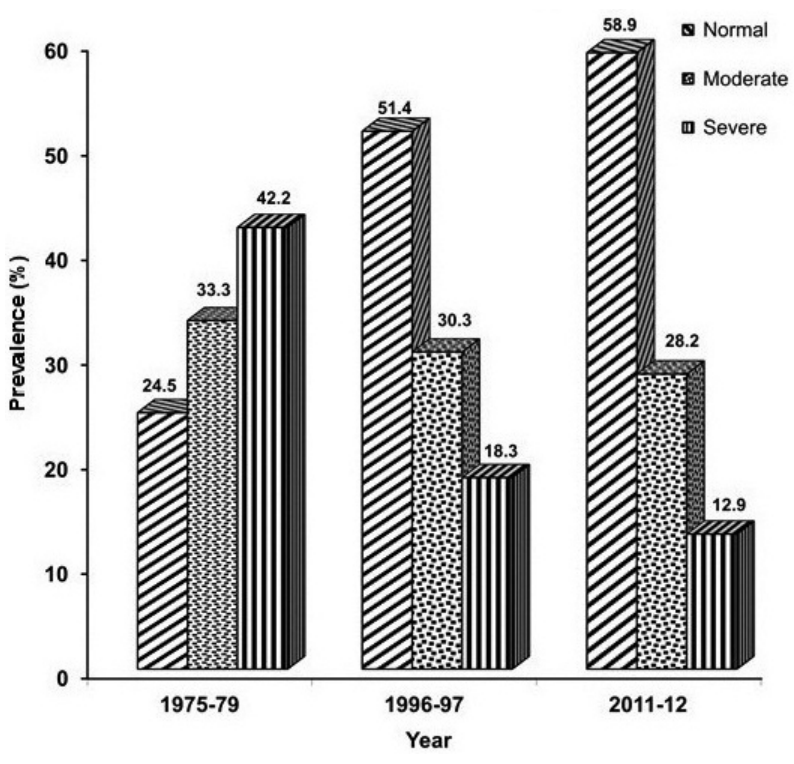

Fig. 3: Time trends in Underweight in Children (Source: NNMB Report \# 26, 2012)

Although there was about $44 \%$ reduction in the extent of stunting, from $82 \%$ initially to $45.7 \%$ in 2011 12 , the extent in terms of absolute numbers is still high. There was a threefold increase in the normal height for age from $18 \%$ to $54 \%$ (Fig. 4). Even if India achieves the WHO Assembly's first of the six global nutrition targets for 2025 of $40 \%$ reduction in the extent of stunted in under-5 children, more than 


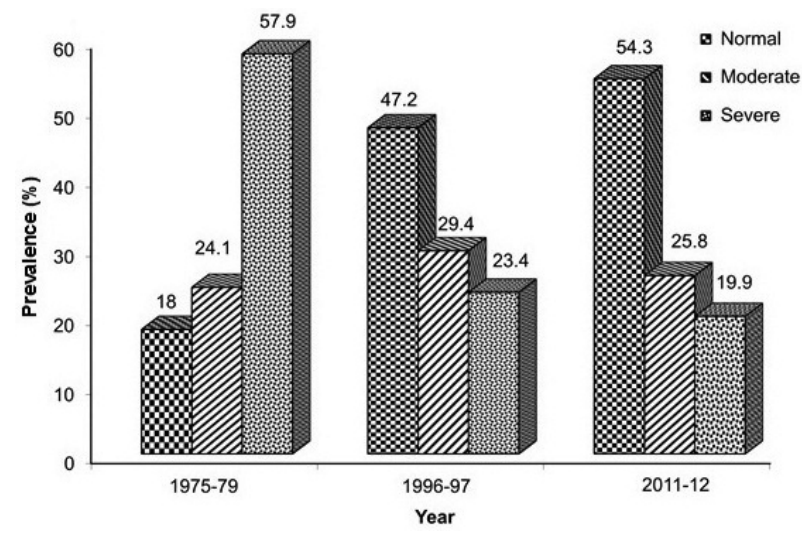

Fig. 4: Time trends in Stunting in Children (Source: NNMB Report \# 26, 2012)

$25 \%$ of children may still be stunted.

Wasting which is an indicator of current or early under-nutrition in children, decreased from about $27 \%$ to about $16 \%$ (Fig. 5).

NFHS presented the extent of underweight in children below the age of 3 years for all the states. The period of survey corresponded to the second and third repeat surveys of NNMB. NFHS-1 did not present the extent of stunting and wasting. The trends observed in NFHS surveys are similar to those observed in NNMB surveys, though there is a marginal variation in the extent, perhaps due to differences in the age groups (Fig. 6).

Analysis of NNMB data indicated that the prevalence of stunting was unaltered during the nineties and showed a decline up to the second repeat survey in 1996-97. The unaltered prevalence during

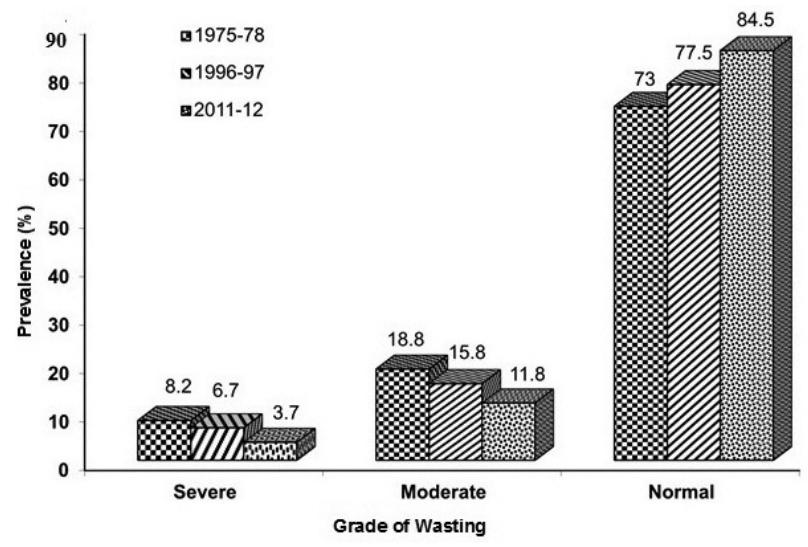

Fig. 5: Time trends in Wasting in children (Source: NNMB Report \# 26, 2012)

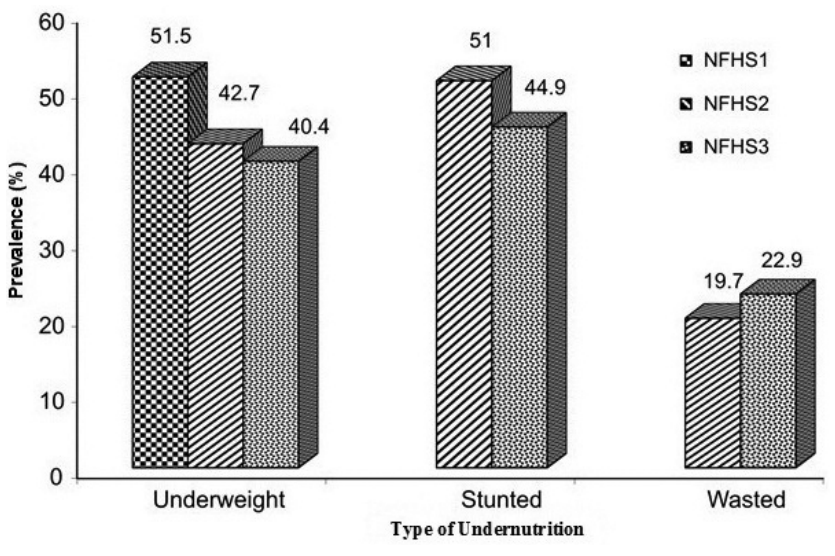

Fig. 6: Time trends in Undernutrition in children (Source: NFHS-3 Report, 2006)

the nineties may be attributed to a negligible decline in poverty. Subsequent decline, particularly in stunting was matched by parallel change in poverty; clearly pointing out that poverty alleviation should receive utmost attention by the Indian planners (Svedberg, 2006).

\section{Trends in Anaemia Prevalence}

NFHS carried out haemoglobin surveys to estimate the prevalence of anaemia in different groups, in its second and third rounds particularly. While the NNMB used the cyanmethemoglobin method, which is considered as gold standard, NFHS used Haemocue method, which is much simpler, particularly for screening under field conditions. However, it has been shown to overestimate haemoglobin by $10-15 \%$, as compared to the gold standard of cyanmethemoglobin method and the prevalence of anaemia hence, is lower as compared to cyanmethemoglobin method (Mayang Sari, 2001, Mohanram et al., 2002, Bhaskaram et al., 2003). Nevertheless, NFHS surveys did not show any decline in the extent of anaemia in children, or nonpregnant non-lactating women or pregnant women, despite the national nutrition anaemia control programme being in operation for over four decades (Fig. 7).

NNMB survey (2003) indicates that the extent of distribution of Iron-Folic Acid tablets under the national nutrition anaemia control programme was in general as low as $3.8 \%$ for children and $12.3 \%$ for lactating mothers. The coverage of pregnant women was, however, better (62.2\%). Even state level evaluations either in Karnataka or Orissa revealed 


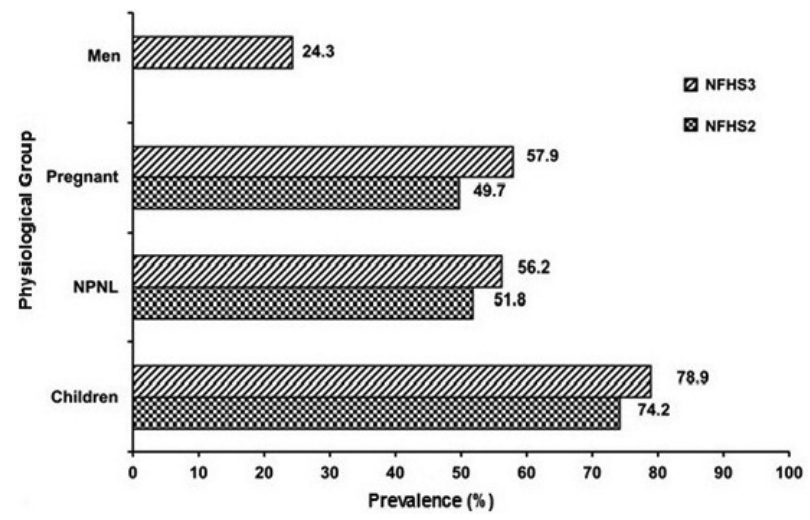

Fig. 7: Time trends in Anemia in different Physiological groups (Source: NFHS-3 Report, 2006)

similar results. What is more important is that the proportion of beneficiaries receiving all the 100 tablets was small. This could explain the absence of any change in anaemia prevalence over time, and points to the need for better administrative efficiency in programme implementation.

\section{Time Trends in Adult Nutrition}

There was a gradual but significant reduction (27\%) in the prevalence of CED among adult males (BMI $<18.5$ ) over the four decade follow-up period, with a gradual increase in over-weight and obesity $\left(\mathrm{BMI} \geq 23.0 \mathrm{~kg} / \mathrm{m}^{2}\right)$ (Fig. 8). Similar decline in the prevalence CED (20\%) and almost five-fold increase in the prevalence of overweight/obesity was noticed among the adult females (Meshram et al., 2015).

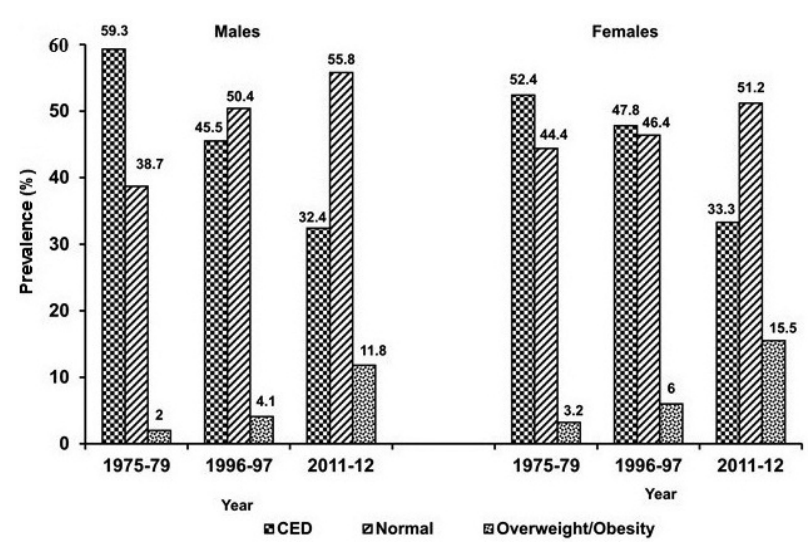

Fig. 8: Time trends in BMI in Adults (Source: NNMB Report \# 26, 2012)

\section{Way Ahead}

Though there has been a perceptible decline in undernutrition over the last 2-3 decades, malnutrition continues to be a widespread public health crisis in India and remains a home to 191 million malnourished people, or 16 per cent of its population. To put this in the global context, 35 per cent of the world's low birth weight infants and 43 per cent of the world's malnourished live in India (Mahbub, 2016). An appraisal of the possible factors for the current situation might provide answers to the future. The biggest denominator for the widespread prevalence of under-nutrition in India is poverty. About $60 \%$ of children in the poorest quintile are stunted (Table 3 ) while the prevalence reduced with improvement in socio-economic status, with only $25 \%$ (which is still high) in the richest quintile showing stunting (UNICEF, 2009). This indicates the significant role of poverty alleviation in controlling under-nutrition. Despite the sharp decline in the incidence of poverty between 2004 and 2011, about 22\% remain poor in the rural areas.

Increasing economic growth of a nation, which is generally measured through increases in per-head gross domestic product (GDP), is often assumed to lead to improvement in health and nutrition of populations. For e.g., Smith and Haddad (2002), based on data from 63 low and middle-income countries with measurements from 1970 to 1996, reported a strong inverse association between national economic growth and childhood underweight. However, Vollmer

Table 3: Relationship between Poverty and Stunting (\%)

\begin{tabular}{lccccc}
\hline Nutritional status & \multicolumn{5}{c}{ Quintile } \\
\cline { 2 - 6 } & Poorest & 2nd & Middle & 4th & Richest \\
\hline Stunting \% & 60 & 54 & 49 & 41 & 25 \\
\hline
\end{tabular}

Source: UNICEF, 2009

Table 4: Trends in Food Consumption Expenditure to Total Expenditure - NSSO

\begin{tabular}{lccccc}
\hline Particulars & \multicolumn{5}{c}{ Years } \\
\cline { 2 - 6 } & $\begin{array}{c}1987- \\
1988\end{array}$ & $11993-$ & $1999-$ & $2004-$ & $2009-$ \\
& 64.0 & 63.2 & 59.4 & 55.0 & 53.6 \\
\hline $\begin{array}{l}\text { \%Food to total } \\
\text { consumption } \\
\text { expenditure }\end{array}$ & & & & & \\
\hline
\end{tabular}

Source: NSSO, 2010 
et al. (2004) found a quantitatively insignificant change between increases in per capita GDP and reduction in early childhood under-nutrition. In India which accounts for the largest national share of the global burden of under-nutrition, substantial increases in economic growth that the country experienced over the past two decades did not translate into a corresponding substantial reduction in childhood undernutrition (Subramanian and Subramanyam, 2011). The reasons could be: unequal distribution of the fruits of growth. Poor people may be excluded from the benefits of growth due to distributive injustice, leading to little or no impact of increased prosperity on the nutrition and wellbeing of the poor. The second reason may be that even if rising incomes reach most households, they might not necessarily be spent in ways that enhance the nutritional status of children. Third reason could be that rising average incomes could be poorly associated with improvements to public services that are essential to improve the nutritional status of the population (e.g., vaccinations against diseases that can precipitate and maintain undernutrition, prenatal and postnatal care, clean water and sanitation, etc). In other words, progress in undernutrition can be achieved in low-income settings through investments in these public services emphasising the need for direct health investments to improve the nutritional status of children in low-income and middle-income countries (Vollmer et al., 2004).

The Economic Survey of India (2015-16) recognized that investments in maternal nutrition and sanitation and enhancing their effectiveness by changing social norms can help India exploit its demographic dividend. The survey acknowledged that a healthy mother is more likely to give birth to a healthy baby, and returns on human capital investments being highest for programmes that target young children and in-utero health, thus appreciating the importance of investment during the first 1000 days of a child's life.

The Global Hunger Index (GHI), which is based on the proportion of under-nourished people as a percentage of the population; the proportion of children under the age of five who suffer from wasting; the proportion of children under the age of five who suffer from stunting and the mortality rate of children under the age of five, designed by the IFPRI measures and tracks hunger globally and by country. There has been a gradual improvement in the GHI between 1990 (48.1) and 2015 (29), though it denotes that hunger is still serious in India (Grebmer et al., 2015). NSSO consumption expenditure surveys (2009-2010) also corroborate this with the observation that, between 1987-88 and 2009-10 there was a $10 \%$ reduction in food expenditure to total (Table 4), except for small increase in the lowest income group (NSSO, 2011).

Despite wide-spread distribution of subsidized foods through PDS to the BPL families, there is only small increase in energy consumption but a decline in pulse consumption among the poor due to continuous escalation of pulse price. This calls for a focus on food production policy. Dietary diversification, observed mainly in urban middle and high-income groups seems a distant hope for the poor. The Eleventh Five Year Plan recognizes nutrition as critical for ensuring the health, survival and development of children and women by developing a framework for a multi-sectoral National Plan of Action to prevent and reduce under-nutrition in a time-bound manner and highlights the need for accelerated action to prevent and reduce maternal and child under-nutrition across the life cycle (Planning Commission of India, 2010). In the Lancet series on maternal and child nutrition, Bhutta et al. (2008), based on a detailed analytical review of interventions, showed that existing interventions which were designed to improve nutrition and prevent related disease could reduce stunting at 36 months by $36 \%$; mortality between birth and 36 months by about $25 \%$; and disability-adjusted life-years associated with stunting, severe wasting, intrauterine growth restriction, and micronutrient deficiencies by about $25 \%$. The interventions were promotion of breastfeeding; strategies to promote complementary feeding, with or without provision of food supplements; micronutrient interventions; general supportive strategies to improve family and community nutrition; and reduction of disease burden (promotion of hand-washing and strategies to reduce the burden of malaria in pregnancy). To eliminate stunting in the longer term, these interventions should be supplemented by improvements in the underlying determinants of under-nutrition, such as poverty, poor education, disease burden, and lack of women's empowerment. Horton and Selina (2013) comment that as sustainable development becomes the dominant idea, nutrition emerges as the quintessential example of a sustainable development objective. If maternal 
and child nutrition is optimised, the benefits will accrue and extend over several generations. Nutritionsensitive interventions and programmes in agriculture, social safety nets, early child development, and education have enormous potential to enhance the scale and effectiveness of nutrition-specific

\section{References}

Bhaskaram $\mathrm{P}$, Balakrishna $\mathrm{N}$, Radhakrishna $\mathrm{K} \mathrm{V}$ and Krishnaswamy K (2003) Validation of hemoglobin estimation using Hemocue, Indian J Pediatr 70 25-8

Bhutta Z A, Ahmed T, Black R E, Dewey S C K, Gugliani E, Kirkwood B, Haldar B, Moms S S, Sachdev H P S, and Sekhar M (2008) The Maternal and Child Under-nutrition Study Group, What works? Interventions for maternal and child under-nutrition and survival Lancet 371 417-440

Department of Women \& Child Development (1993) National Nutrition Policy Ministry of Human Resource Development Government of India http://wcd.nic.in/sites/ default/files/nnp_0.pdf

Department of Women and Child development (1995) The National Plan of Action on Nutrition Ministry of Human Resource Development Government of India http:// www.wcd.nic.in/fnb/fnb/Publications/FNB\%20Booklets/ national\%20Plan\%20of\%20Action.pdf

Government of India (2015) Rapid Survey on Children 20132014 - India Fact sheet, Ministry of Ministry of Human Development http://wcd.nic.in/issnip/National_ Fact\%20sheet_RSOC\%20_02-07-2015.pdf

Gillespie S and Flores R (2000) The life cycle of malnutrition International Food Policy Research Institute (IFPRI)

Grebmer K V, Bernstein J, Prasai N, Yin S and Yohannes Y (2015) 2015-Global Hunger Index: Armed Conflict and the Challenge of Hunger, International Food Policy Research Institute https://www.ifpri.org/publication/2015global-hunger-index-armed-conflict-and-challenge-hunger

Horton R and Lo S (2013) Nutrition: a quintessential sustainable development goal Comment Lancet 382 371-372

International Institute of Population Sciences, (1995) National Family Health Survey-India, International Institute of Population Sciences

International Institute of Population Sciences (1998-99), Reproductive and Child Health Project India - Rapid Household Survey, International Institute of Population Sciences interventions (Ruel and Alderman, 2013). It should be recognized that intent and policy alone are not adequate. Urgent changes are needed to bridge the gap between the policy intentions and actual implementation.

International Institute of Population Sciences (2006) National Family Health Survey 3 - India Report, International Institute of Population Sciences

International Institute of Population Sciences (2010) Report of District Level Household and Facility Survey 2007-08, International Institute of Population Sciences http:// rchiips.org/pdf/rch1/National_Report_RCH-1.pdf

International Food Policy Research Institute (2015) Global Nutrition Report 2015: Actions and Accountability to Advance Nutrition and Sustainable Development. International Food Policy Research Institute

Mahbub R (2016) An analysis of India's newly-released national budget: Do the numbers add up when it come nutrition? Results for Development http://r4d.org/blog/2016-04-19/ analysis-india\%E2\%80\%99s-newly-released-nationalbudget-do-numbers-add-when-it-comes

Sari M, de Pee S, Elviyanti M, Herman S, Sugiatmi, Martin W Bloem and Yip R (2001) Estimating the prevalence of anaemia: A comparison of three methods Bulletin of the World Health Organization 79 506-511

Meshram I I, Balakrishna N, Sreeramakrishna K, Rao K M, Hari Kumar R, Arlappa N, Manohar G, Gal Reddy Ch, Ravindranath M, Sharad Kumar S, Brahmam G N V and Laxmaiah A (2015) Trends in nutritional status and nutrient intakes and correlates of overweight/obesity among rural adult women (e"18-60 years) in India: National Nutrition Monitoring Bureau (NNMB) national surveys Asia-Pacific Journal of Public Health 27 NP1345-NP1361, 7

Mohan Ram M, Rao G V and Sastry J G (2002) A comparative study on prevalence of anaemia in women by cyanmethaemoglobin Indian Journal of Community Medicine 27 58-61

Nandy S, Kelly M, Gordon D, Subramanian S V and Smith G D (2005) Poverty, child under-nutrition and morbidity: new evidence from India Bull World Health Organization $\mathbf{8 3}$ 210-16

National Food Security Act (2013) The Gazette of India Extraordinary, Part II, No.29, Government of India, http:/ /indiacode.nic.in/acts-in-pdf/202013.pdf 
National Nutrition Monitoring Bureau (2003) Prevalence of Micronutrient deficiencies, NNMB Technical Report No. 22, National Institute of Nutrition

National Nutrition Monitoring Bureau (2006) Prevalence of vitamin A Deficiency among preschool children in rural areas, NNMB Technical Report No: 23, National Institute of Nutrition

National Nutrition Monitoring Bureau (2012) Diet and Nutritional Status of Rural Population, Prevalence of hypertension \& Diabetes among Adults and Infant \& Young Child Feeding Practices - Third Repeat survey, NNMB Technical Report No. 26, National Institute of Nutrition

National Sample Survey Organisation (2011) Level and pattern of consumer expenditure, NSSO Report 538, Ministry of Statistics and Programme Implementation http:// mospi.nic.in/Mospi_New/upload/NSS_Report_538.pdf

Planning Commission of India (2010) Addressing India's Nutrition Challenges, Report of the Multi-stakeholder Retreat, Planning Commission, Government of India

Ruel M T and Alderman $\mathrm{H}$ and the Maternal and Child Nutrition Study Group (2013) Nutrition-sensitive interventions and programmes: how can they help to accelerate progress in improving maternal and child nutrition? Lancet 382 53651

Smith L C and Haddad L (2002) How potent is economic growth in reducing under-nutrition? What are the pathways of impact? New cross-country evidence Econ Dev Cult Change 51 55-76

Subramanian S V and Subramanyam MA(2011) Economic growth $\&$ health of poor children in India Indian J Med Res 133 685-686

Svedberg P (2006) Declining child malnutrition: a reassessment International Journal of Epidemiology 35 1336-1346

UNICEF (2004) Low Birth Weight, Country, Regional and global Estimates UNICEF
UNICEF (2009) Tracking progress on child and maternal nutrition - A survival and development priority UNICEF

UNICEF-WHO-The World Bank project (2012) Global Database on Child Growth and Malnutrition-2012 Joint child malnutrition estimates - Levels and trends http:// www.who.int/nutgrowthdb/estimates2012/en

UNICEF (2013) Improving Child Nutrition The achievable imperative for global progress UNICEF

UNICEF (2014) Global Database, Low birth weight Incidence and Trends http://data.unicef.org/nutrition/lowbirthweight.html

UNSCN (2004") 5th Report on the World Nutrition Situation: Nutrition for Improved Development Outcomes. United Nations System Standing Committee on Nutrition http:// www.unscn.org/layout/modules/resources/files/rwns5.pdf

Vijayaraghavan K, Prakasam B S and Laxmaiah A (2002) Time Trends in the intra-family distribution of dietary energy in rural India Food \& Nutrition Bulletin 23 390-394

Vollmer S, Harttgen K, Subramanyam M A, Finlay J, Klasen S and Subramanyam S V (2004) Association between economic growth and early childhood under-nutrition: evidence from 121 Demographic and Health Surveys from 36 low-income and middle-income countries The Lancet Global Health 2 e225-e234

WHO (1996) Indicators for assessing vitamin A deficiency and their application in monitoring and evaluation intervention programmes World Health Organization http://www.who. int/nutrition/publications/micronutrients/vitamin_a_ deficieny/WHONUT96.10.pdf

WHO (2010) Nutrition Landscape Information System (NLIS) country profile indicators: interpretation guide, WHO http://apps.who.int/iris/bitstream/10665/44397/1/ 9789241599955_eng.pdf?ua=1

WHO (2014) Comprehensive implementation plan on maternal infant and young child nutrition, WHO/NMH/NHD/14.1, WHO http://apps.who.int/iris/bitstream/10665/113048/1/ WHO_NMH_NHD_14.1_eng.pdf. 